Kong. Res. J. 1(2): 105-108, 2014

Kongunadu Arts and Science College, Coimbatore

\title{
PHYSICO AND PHYTO-CHEMICAL ANALYSIS OF PLUMBAGO ZEYLANICA L. - A POTANT INDIAN HERB
}

\author{
Sharmila, $\mathbf{S}^{*}$., K. Kalaichelvi and G. Jayanthi \\ Department of Botany, Vellalar College for Women, Thindal, Erode. \\ *E-mail: drsharmilas@yahoo.com
}

\begin{abstract}
Medicinal plants are an integral component of alternative medical care. For millennia, Indian people traditionally played an important role in the management of biological resources and were custodians of related knowledge that they acquired through trial and error over centuries. India has a rich wealth of medicinal plants and the potential to accept the challenge to meet the global demand for them. In recent time, focus on plant research has increased all over the world and a large body evidence has collected to show immense potential of medicinal plants used in various traditional system. Plumbago zeylanica L. (Plumbaginaceae) is a tropical plant and the source for the well known ayurvedic drug 'chitrakah'. Different parts of this plant are widely used for variety of medicinal treatments. Especially used for appetite, indigestion, piles, worms, liver diseases and cancer treatments. The present study was therefore carried out to provide pharmacognostic details of root of Plumbago zeylanica. The physico-chemical analysis of ash content indicated the presence of inorganic matter and siliceous matter in the drug. The phytochemical analysis indicated the presence of alkaloids, phenols, flavonoids, tannins and terpenoids. Plumbagin is a naturally occurring yellow pigment, produced by member of plumbaginaceae that can be obtained from roots.
\end{abstract}

Keywords: Medicinal plants, traditional, ayurvedic, chitrakah, cancer, plumbagin

\section{INTRODUCTION}

The use of plants in ethnomedicine is increasing around the world. The World Health Organization (WHO) has reported that approximately $80 \%$ of the world's population currently uses herbal medicines (Kalidass et al., 2010). Herbal drugs are widely prescribed, even when their biological components are not known, as a result of their effectiveness, fewer side effects and relatively low cost (Kumar et al., 2009). The main source of drugs for Indian system of medicine, majority of the Indian population depends on phytomedicine for their primary health care in this modern scientific world (Thinakaran et al., 2009). In recent time, focus on plant research has increased all over the world and a large body evidence has collected to show immense potential of medicinal plants used in various traditional system. Silver and Bostian (1993) have documented the use of natural products as new antibacterial drugs. There is an urgent need to identify novel substances active towards highly resistant pathogens (Cragg et al., 1997). In an effort to discover new compounds, many research groups screen plant extracts to detect secondary metabolites with the relevant biological activities. In this regard, several simple bioassays have been developed for screening purposes (Hostettmann, 1991).
The present study was carried out on the phyto-chemical analysis of root extract of Plumbago zeylanica L. (Plumbaginaceae) which is a tropical shrub commonly distributed in forest of the Uttarakhand, India and cultivated in the gardens throughout India. The plant is commonly known as Ceylon Leadwort (English) and Chitramoolam (Tamil). Plumbago zeylanica is the source for the well known ayurvedic drug ' Chitrakah'. The whole plant, roots, powder of the root, leaves and stembark are widely used as medicinal herbs throughout Asia and Africa. In traditional herbal medicine, the root park of Plumbago zeylanica is used for treatment of different ailments such as parasitic diseases, scabies and ulcers (Olagunju et al., 2006), piles, diaarrhoea, skin diseases and leprosy (Uma et al., 1999), fever, rheumatism, intestinal parasites, anemia, swelling and scabies (Jeyachandran et al., 2009), antimicrobial (Ahmad et al., 2000), antioxidant and anti-inflammatory (Raimi and Oyedapo, 2009), antiplasmodial (Simonsen et al., 2001) and anti-insecticidal (Arunachalam et al., 2010).

\section{MATERIALS AND METHODS}

\subsection{Plant Material}

The root parts of $P$. zeylanica $L$. were collected from Kolinchamparai, Palakkad (Palghat), Kerala, India (Plate-1). Collected specimens were 
carefully examined and identified with the help of regional floras (Kirithkar and Basu, 1980). Specimens were further confirmed with reference to herbarium sheet available in the Botanical Survey of India, Southern Circle, Coimbatore.

\subsection{Preparation of extract}

The roots were separated from the stalks and thoroughly but gently rinsed with tap water thrice to remove sands then oven dried completely at 27 to $30^{\circ} \mathrm{C}$ for 1 week. The dried roots were ground to fine powder using a local grinder (Plate2). $150 \mathrm{~g}$ of the powdered root was exhaustively extracted in alcohol, chloroform and petroleum ether with soxhlet extractor and then concentrated using rotary vacuum evaporator. $10 \mathrm{ml}$ extract was measured out from the concentrate for phytochemical screening while the remaining extract was evaporated to complete dryness at $35^{\circ} \mathrm{C}$ given a dark brown colour solid residue. The dried extract was stored in airtight container and placed in refrigerator.

\subsection{Physico and Phyto-chemical screening}

The macroscopic study of a medicinal plant was helpful in rapid identification of plant material and also plays an important role in standardization of drug. The fresh root was subjected to macroscopic studies which comprised of organoleptic characters viz., color, odour, appearance, taste, texture etc. Organoleptic characters (colour, odour, taste, texture) of root powder and the successive extracts were observed and recorded (Evans, 1983). Behaviour of plant powder with different chemical reagents (Kokoshi et al., 1958), Determination of moisture content (Anonymous, 1966) and Ash values (Evans, 1983) were observed and recorded. Preliminary phytochemical screening were carried out for alkaloids, phenolics, flavonoids, steroids, sterols, tannins, sugars and terpenoid (Harborne, 1984; Kokate et al., 1995).

\section{RESULTS AND DISCUSSION}

The organoleptic evaluation of the root powder of P. zeylanica showed characteristic odour and pungent taste. Upon drying and powdering the colour of the powder changed from light brown to reddish brown as shown in Table 1. The organoleptic characters such as colour, consistency and odour were noted in the successive root extracts (Table 2). The behaviour of root powder with different chemical reagents were observed and presented in Table 3. The physico-chemical characters of the sample were analysed and presented in Table 4. Loss on drying at $105^{\circ}$ is determined since the presence of excess moisture is conducive to the promotion of mould and bacterial growth and subsequently to deterioration and spoilage of the drug (Ariyanathan et al., 2010; Pravin Sopan Borhade et al., 2014). The physico-chemical analysis indicated the $3.11 \%$ of ash content which is due to the presence of inorganic matter. Acid insoluble ash indicates the presence of more siliceous matter $(0.96 \%)$ in the drug.

Plants are considered as bioreactors or biosynthetic laboratories as they synthesize wide range of characteristic therapeutically important molecules in the form of secondary metabolites. Thus, a systematic preliminary phytochemical screening of plant material is essential for identifying plant constituents and to establish a chemical profile of a crude drug for its proper evaluation (Pravin Sopan Borhade et al., 2014). The benzene soluble extractive reveals the presence of flavonoids, steroids, sterols, tannins, sugar and terpenoids. The chloroform soluble extract reveals the presence of steroids, sterols and terpenoids. The ethanol soluble extract reveals the presence of alkaloids, phenols, flavonoids and sugars. The water soluble extract reveals the presence of phenols, flavonoids and sugars. In the preliminary phytochemical analysis, P. zeylanica (Table 5) showed the presence of secondary metabolites like alkaloids, phenols, flavonoids, Tannins and Terpenoids (Dhale and Markandeya, 2011).

\section{CONCLUSION}

Preliminary phyto-chemical as well as various aspects of the sample were studied and described along with physico-chemical and microscopic studies in authentication, adulteration for quality control of raw drugs. Preliminary phytochemical analysis showed the presence of secondary metabolites like alkaloids, Phenols, flavonoids, tannins, and terpenoids. These studies will help in proper identification of the plant as a whole and its powder form for future studies.

\section{REFERENCES}

Thinakaran, T., A. Rajendran and V. Sivakumari, (2009). Pharmacognostical, Phytochemical and Pharmacological studies in Rauvolfia tetraphylla L. Asian Jour.of Environ.Science. 4(1): 81-85.

Kalidass, C., A. Daniel and VR. Mohan, (2010). Rapid propagation of Plumbago zeylanica L. An important medicinal plant. J. Am. Sci. 6 (10): 1027-1031.

Kumar, R., S. Kumar, A. Patra and S. Jayalakshmi, (2009). Hepatoprotective activity of aerial 
plants of Plumbago zeylanica L. against carbon tetrachloride-induced hepatotoxicity in rats. Int. J. Pharm. Sci. 1(1): 171-175.

Thinakaran, T., A. Rajendran and V. Sivakumari, (2009). Pharmacognostical, phytochemical and pharmacological studies in Rauvolfia tetraphylla L. Asian J. of Environ. Science. 4(1):81-85.

Silver, L.L. and K.A. Bostain, (1993). Discovery and development of new antibiotics: The problem of antibiotic resistance. Antimicrobial Agents and Chemotherapy. 37: 377-383.

Cragg, G.M., D.J. Newman and K.M. Snader, (1997). Natural products in drug discovery and development. J. of Natural products. 60:52-60.

Hostettmann, K. (1991). Assays for bioactivity Methods in Plant Biochemistry, Academic Press, San Diego. 6, 360.

Olagunju, JA., BS. Fagbohunka, O. Oyedapo and AIA. Abdul, (2006). Effects of an ethanolic root extract of Plumbago zeylanica L. on some serum parameters of the rats. RPMP-Drug Dev. Mol. 11: 268-276.

Uma DP., FE. Soloman and AC. Sharda, (1999). Indian medicinal plants and their roots. Pharm. Biol. 37: 231-236.

Jeyachandran, R., A. Mahesh, L. Cindrella, S. Sudhakar and K. Pazhanichamy (2009). Antibacterial activity of Plumbagin and root extracts of Plumbago zeylanica. Acta Biol. Cracoviensia Ser. Botan. 51(1): 17-22.
Ahmed, I., Z. Mehmood, F. Mohammad and S. Ahmad, (2000). Antimicrobial potency and synergistic activity of five traditionally used Indian medicinal plants. J. Med. Arom. Plant Sci. 23: 173-176.

Raimi, MM and O. Oyedapo, (2009). Bioactivityguided evaluation of the root extract of $P$. zeylanica. Int. J. Biol. Chem. Sci. 3(4): 47.

Simonsen, HT., JB. Nordskjold, UW. Smitt, Nyman, P. Palpu and G. Varughese, (2001). In vitro screening of Indian medicinal plants for antiplasmodial activity. J. Ethnopharmacol. 74: 195-204.

Arunachalam, KD., P. Velmurugan and RB. Raja, (2010). Anti-inflammatory and cytotoxic effects of extract from P. zeylanica. Afri. J. Microbiol. Res. 4(12): 1239-1245.

Ariyanathan, S., A. Saraswathy and G.V. Rajamanickam, (2010). Quality control standards for the Roots of three Plumbago sps. Indian J. Pharm. Sci. 72(1), 86-91.

Dhale, D.A. and S.K. Markandeya, (2011). Antimicrobial and phytochemical screening of Plumbago zeylanica L. (Plumbaginaceae) Leaf. J. of Experimental Sciences. 2(3), 4-6.

Pravin Sopan Borhade, Tushar Atmaram Deshmukh, Vijay Raghunath Patil and Kishanchnad Radhesham Khandelwal, (2014). Pharmacognostic and Phytochemical Investigations of Plumbago zeylanica Linn. Root, Journal of Pharmacognosy and Phytochemistry. 2 (6): 83-88.

Table 1: Organoleptic characters of root powder of P. zeylanica

\begin{tabular}{ccc}
\hline S.No. & Characters & Observations \\
\hline 1. & Colour & Reddish brown \\
2. & Texture & Fine smooth powder \\
3. & Taste & Pungent \\
4. & Odour & Characteristic smell \\
\hline
\end{tabular}

Table 2: Organoleptic characters of plant root successive extracts of $P$. zeylanica

\begin{tabular}{cllll}
\hline S.No. & \multicolumn{1}{c}{ Extraction Medium } & \multicolumn{1}{c}{ Colour } & \multicolumn{1}{c}{ Consistency } & \multicolumn{1}{c}{ Odour } \\
\hline 1. & Alcohol & Light brown & Semi solid & Characteristic smell \\
2. & Chloroform & Brownish black & Semi solid & Characteristic smell \\
3. & Petroleum ether & Brownish black & Solid & Characteristic smell \\
\hline
\end{tabular}


Table 3: Behaviour of root powder of $P$. zeylanica with different chemical reagents

\begin{tabular}{lll}
\hline S.No. & Powder + Reagents used & Colour of the powder \\
\hline 1. & Powder as such & Pale brown \\
2. & Powder + Concentrated $\mathrm{HCL}$ & Wood brown \\
3. & Powder + Concentrated $\mathrm{HNO}_{3}$ & Yellowish \\
4. & Powder + Concentrated $\mathrm{H}_{2} \mathrm{SO}_{4}$ & Greenish brown \\
\hline
\end{tabular}

Table 4: Physico-chemical and extractive values of root powder of $P$. zeylanica

\begin{tabular}{lll}
\hline S.No. & Physico-chemical properties & Values in percentage (\%) \\
\hline 1. & Moisture content & 8.18 \\
2. & Total ash & 3.11 \\
3. & Acid insoluble ash & 0.96 \\
4. & Water soluble ash & 2.27 \\
5. & Alcohol-soluble extractive & 12.83 \\
5. & Crude fibre content & 14.30 \\
\hline
\end{tabular}

Table 5: Qualitative analysis of root extracts of $P$. zeylanica

\begin{tabular}{|c|c|c|c|c|c|}
\hline S.No. & Phytochemical constituents & Ben & $\mathrm{CHCl}_{3}$ & $\mathrm{E}$ & $\mathrm{H}_{2} \mathrm{O}$ \\
\hline 1. & Alkaloids & - & - & + & - \\
\hline 2. & Phenols & . & - & + & + \\
\hline 3. & Flavonoids & + & - & + & + \\
\hline 4. & Steroids, sterols & + & + & - & - \\
\hline 5. & Tannins & + & - & - & - \\
\hline 6. & Sugar & + & - & + & + \\
\hline 7. & Terpenoids & + & + & - & - \\
\hline
\end{tabular}

Note : '+', '-' indicates the presence / absence of compounds. (Ben) Benzene (CHCl3), Chloroform, (E) Ethanol, (H2O) Water.

\section{PLATE-I}

Plumbago zeylanica - Habit

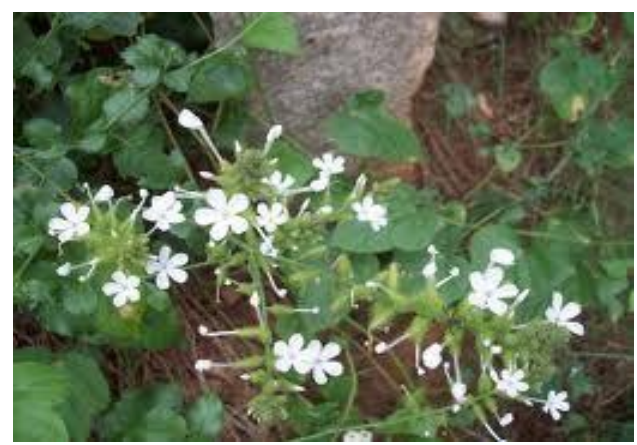

PLATE-II

Plumbago zeylanica - Root Plumbago zeylanica - Root Powder
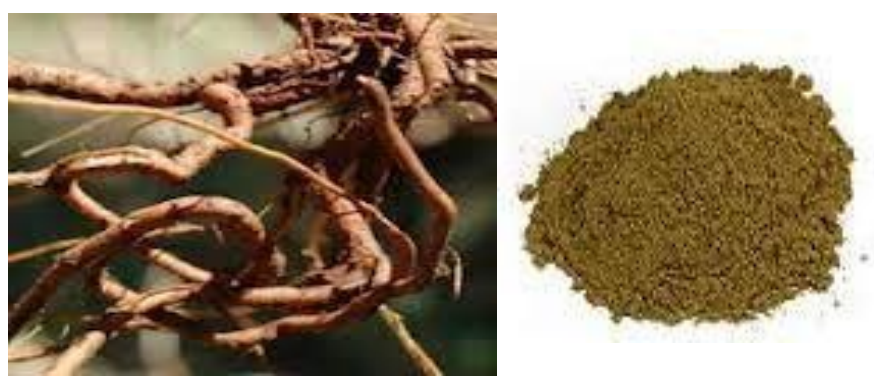